\title{
A new species of Diplatys (Insecta, Dermaptera, Diplatyidae) earwig from the Western Ghats of India
}

\author{
Chikkabidare M. Karthik', Yoshitaka Kamimura², \\ Chicknayakanahalli M. Kalleshwaraswamy'
}

I Department of Entomology, College of Agriculture, Keladi Shivappa Nayaka University of Agricultural and Horticultural Sciences, Navile, Shivamogga - 577204, Karnataka, India 2 Department of Biology, Keio University, 4-1-1 Hiyoshi, Yokohama 223-8521, Japan

Corresponding author: Yoshitaka Kamimura (kamimura@keio.jp)

Academic editor: Fabian Haas | Received 16 December 2021 | Accepted 15 February 2022 | Published 7 March 2022

http://zoobank.org/1EFOAEF0-177D-44AE-8BCF-0D1F41EDAC50

Citation: Karthik CM, Kamimura Y, Kalleshwaraswamy CM (2022) A new species of Diplatys (Insecta, Dermaptera, Diplatyidae) earwig from the Western Ghats of India. ZooKeys 1088: 53-64. https://doi.org/10.3897/ zookeys. 1088.79416

\begin{abstract}
To explore diversity of earwigs (Dermaptera) in different agricultural ecosystems of South India, an extensive taxonomic survey was conducted in 2020 during which an undescribed species of Diplatys was collected. Twenty-one species of the genus Diplatys (Diplatyidae, Diplatyinae) have been reported to date from India, of which six species are known from Karnataka, South India. Based on a male specimen collected from a sugarcane field in Karnataka, a new species, Diplatys sahyadriensis sp. nov., is described as the twenty-second species of this genus from India. A revised key to the males of Diplatys species from India and Sri Lanka is provided. This new record adds to the known species diversity in the Sahyadri Ranges of the Western Ghats in Shivamogga District, Karnataka, part of the Southern Plateau and Hills agro-climatic region of India.
\end{abstract}

\section{Keywords}

Diplatys sahyadriensis sp. nov., Karnataka, Sri Lanka, sugarcane

\section{Introduction}

Earwigs are a moderately diversified group of insects which comprise approximately 1,900 species distributed mainly in tropical and subtropical parts of the world (Hopkins et al. 2018). The previous taxonomic study by Srivastava (2013) reported 284 species

Copyright C. M. Karthik et al. This is an open access article distributed under the terms of the Creative Commons Attribution License (CC BY 4.0), which permits unrestricted use, distribution, and reproduction in any medium, provided the original author and source are credited. 
from India. Although the taxonomy is unstable and unsettled, the genus Diplatys (Diplatyidae), in a broad sense, is species rich with approximately 70 described species from the Ethiopian and Oriental regions (Hopkins et al. 2018). According to the system of Srivastava $(1988,2013), 25$ species of Diplatys have been reported from India and Sri

Table I. Distribution and subgeneric classification of Diplatys species recorded from India and Sri Lanka.

\begin{tabular}{|c|c|c|c|c|c|c|c|c|}
\hline \multirow[t]{2}{*}{ Species } & \multirow{2}{*}{$\begin{array}{c}\text { Subgenus by } \\
\text { Steinmann } \\
(1986 b)\end{array}$} & \multicolumn{6}{|c|}{ Distribution } & \multirow[t]{2}{*}{ Sri Lanka } \\
\hline & & $\begin{array}{c}\text { Highland } \\
\text { (Himalayas } \\
\text { \& N.E. } \\
\text { mountains) }\end{array}$ & $\begin{array}{c}\text { Humid } \\
\text { Subtropical }\end{array}$ & $\begin{array}{l}\text { Tropical Wet } \\
\text { and Dry }\end{array}$ & Arid & Semiarid & $\begin{array}{c}\text { Tropical } \\
\text { Wet }\end{array}$ & \\
\hline D. adjacens Hincks, 1955 & (Syndiplatys) & & $\begin{array}{c}\text { Uttarakhand }^{1} \text {, } \\
\text { Madhya } \\
\text { Pradesh }^{1}\end{array}$ & $\begin{array}{l}\text { Madhya } \\
\text { Pradesh }^{1}\end{array}$ & & & & \\
\hline $\begin{array}{l}\text { D. anamaliensis Srivastava, } \\
1970\end{array}$ & (Syndiplatys) & & & & & $\begin{array}{l}\text { Tamil } \\
\mathrm{Nadu}^{1}\end{array}$ & & \\
\hline D. brindlei Steinmann, 1974 & (Neodiplatys) & $\begin{array}{c}\text { Central } \\
\text { Himalaya }^{3}\end{array}$ & West Bengal ${ }^{1,4}$ & & & & & \\
\hline D. carinatus Srivastava, 1988 & Not assigned & & & Karnataka $^{1}$ & & & Karnataka $^{1}$ & \\
\hline D. carli Srivastava, 1988 & Not assigned & & & Tamil Nadu ${ }^{1}$ & & & & \\
\hline D. chopardi Hincks, 1955 & (Neodiplatys) & & & $\begin{array}{l}\text { Karnataka }^{1} \\
\text { Tamil Nadu }\end{array}$ & & $\begin{array}{l}\text { Tamil } \\
\text { Nadu }^{1}\end{array}$ & & \\
\hline $\begin{array}{l}\text { D. chowdhuryi Srivastava, } \\
1989\end{array}$ & Not assigned & & & Odisha $^{2}$ & & & & \\
\hline D. coelebs Hincks, 1955 & (Syndiplatys) & & & $\begin{array}{l}\text { Maharashtra }{ }^{1} \text {, } \\
\text { Tamil Nadu }\end{array}$ & & & $\begin{array}{c}\text { Karnataka } \\
\text { Kerala }^{1}\end{array}$ & \\
\hline D. confusus Hincks, 1955 & (Syndiplatys) & & & Tamil Nadu ${ }^{1}$ & & $\begin{array}{r}\text { Tamil } \\
\mathrm{Nadu}^{1}\end{array}$ & & \\
\hline D. devlensis Srivastava, 1974 & (Hypodiplatys) & & & Tamil Nadu ${ }^{1}$ & & & & \\
\hline D. dolens Hincks, 1957 & (Neodiplatys) & & & Maharashtra $^{1}$ & & & & \\
\hline D. ernesti Burr, 1910 & (Syndiplatys) & & & & & & & $\begin{array}{l}\text { Uva Province }{ }^{1} \text {, } \\
\text { Central Province }\end{array}$ \\
\hline D. excidens Hincks, 1954 & (Neodiplatys) & & & Karnataka $^{1}$ & & & & \\
\hline D. fletcheri Burr, 1910 & (Hypodiplatys) & & $\begin{array}{l}\text { Madhya } \\
\text { Pradesh }^{1}\end{array}$ & Tamil Nadu ${ }^{1}$ & & $\begin{array}{l}\text { Tamil } \\
\mathrm{Nadu}^{1}\end{array}$ & & Uva Province $^{1}$ \\
\hline D. greeni Burr, 1904 & (Syndiplatys) & & & & & & & $\begin{array}{c}\text { Central } \\
\text { Province }^{1} \text {, } \\
\text { Sabaragamuwa } \\
\text { Province }^{1}\end{array}$ \\
\hline $\begin{array}{l}\text { D. jawalagriensis Kapoor, } \\
\text { Bharadwaj \& Banerjee, } 1971\end{array}$ & (Diplatys) & & & $\begin{array}{l}\text { Karnataka }^{1} \\
\text { Tamil Nadu }\end{array}$ & & $\begin{array}{r}\text { Tamil } \\
\mathrm{Nadu}^{1}\end{array}$ & & \\
\hline D. lefroyi Burr, 1910 & (Neodiplatys) & & & Karnataka $^{1}$ & & & & \\
\hline $\begin{array}{l}\text { D. menoni Kapoor \& } \\
\text { Bharadwaj, } 1968\end{array}$ & (Diplatys) & & & Maharashtra $^{1}$ & & & & \\
\hline D. nathani Hincks, 1960 & (Diplatys) & & $\begin{array}{l}\text { Madhya } \\
\text { Pradesh }^{1}\end{array}$ & & & & & \\
\hline D. nilgiriensis Hincks, 1955 & (Syndiplatys) & & & Tamil Nadu ${ }^{1}$ & & & & \\
\hline D. papovi Bey-Bienko, 1959 & (Neodiplatys) & & Meghalaya $^{1}$ & & & & & \\
\hline D. propinquus Hincks, 1955 & (Syndiplatys) & & & & & & & Central Province ${ }^{1}$ \\
\hline D. sahyadriensis sp. nov. & Not assigned & & & Karnataka $^{3}$ & & & & \\
\hline D. santoshi Srivastava, 1975 & (Syndiplatys) & & & & & & & Central Province ${ }^{1}$ \\
\hline D. sinuatus Hincks, 1955 & (Syndiplatys) & $\begin{array}{c}\text { Himachal } \\
\text { Pradesh }^{1,} \\
\text { North } \\
\text { Western } \\
\text { Himalayas }^{3}\end{array}$ & $\begin{array}{c}\text { Bihar }^{1}, \\
\text { Odisha }^{1}, \text { West } \\
\text { Bengal }^{4}\end{array}$ & West Bengal $^{4}$ & & & & \\
\hline D. tikaderi Srivastava, 1988 & Not assigned & & & Odisha $^{1}$ & & & & \\
\hline
\end{tabular}

1. Srivastava (1988), 2. Srivastava (1989), 3. Deepak and Ghosh (2018), 4. Srivastava (1993a) 
Lanka, of which four species are endemic to Sri Lanka (Srivastava 1988, 1989, 2013; Table 1); clearly these two countries represent the centre of Diplatys diversity.

To explore the diversity of earwigs in different agricultural ecosystems of South India, we conducted an extensive taxonomic survey in agricultural and horticultural crop fields. Here we report a new species, D. sahyadriensis sp. nov., based on a male specimen collected from a sugarcane ecosystem. The possible relationships of the new species with other Diplatys recorded from India and Sri Lanka and the diversity of this genus in this region are also discussed.

\section{Materials and methods}

The specimen was collected by hand from a sugarcane field in Shivamogga District, Karnataka, India, and preserved in $70 \%$ ethanol. For the morphological identification, the specimen was examined under a Stemi 508 stereozoom microscope (Carl Zeiss Microscopy GmbH, Jena, Germany). Photographs of the habitus and external body parts were taken under an M205C stereozoom microscope attached with a DFC450 camera (Leica, Wetzlar, Germany). The male genitalia were removed by gently lifting the penultimate abdominal sternite, pulling out from the genital chamber with forceps, and cutting at the site of attachment to the ejaculatory ducts. The genitalia were processed by submerson in $5 \% \mathrm{KOH}$ for two days for clearing tissues and mounted on a glass slide with glycerol. Photographs of dissected genitalia were taken an M205C stereozoom microscope attached with a DFC450 camera. Based on the photographs, the genitalia were illustrated using Adobe Illustrator CS6. The specimen, with voucher number UAHSE19K, is deposited in the Insect Systematics and Vector Biology Laboratory, Department of Entomology, College of Agriculture, Keladi Shivappa Nayaka University of Agricultural and Horticultural Sciences, Shivamogga. The terminology of Kamimura (2014) was adopted to describe male genital structures.

\section{Taxonomy}

Order Dermaptera de Geer, 1773

Infraorder Protodermaptera Zacher, 1910

Family Diplatyidae Verhoeff, 1902

Subfamily Diplatyinae Verhoeff, 1902

Genus Diplatys Audinet-Serville, 1831

Diplatys sahyadriensis Karthik, Kamimura \& Kalleshwaraswamy, sp. nov. http://zoobank.org/3E7D2B09-09B4-437B-93B1-280FEBD35207

Figs 1, 2, Table 2

Material examined. Holotype (ð), India: Karnataka, Hosanagara-Shivamogga Road, Galigekola, 1359'52.854"N, $75^{\circ} 22^{\prime} 42.576 " E$, 6.xi.2020, C.M. Karthik leg., ex. sugarcane. 
Diagnosis. Male has simple forceps, and is easily discriminated from that of other Diplatys species by the unique morphology of the virga: paired portion with developed flanges and a whip-like process at each tip. Flanged virgae have been reported in this genus only for D. jawalagiriensis Kapoor, Bharadwaj \& Banerjee, 1971. However, almost no unpaired part is present at the base of each virga in $D$. jawalagiriensis, with no associated large sclerites in the penis lobe (vs short but conspicuous unpaired part and characteristic associated sclerites are present in D. sahyadriensis sp. nov.).

Description. Male (holotype: Figs 1, 2). Measurements of body parts are shown in Table 2. Body generally dark brown. $2^{\text {nd }}$ antennal segment and beyond light brown. Coxa, trochanter, basal third of femur, distal half of tibia, tarsi, base of tegmina, wings (excluding fustis), lateral and posterior margins of pronotum, and base of forceps whitish brown (Fig. 1a-f). Abdomen and forceps densely pubescent (Fig. 1a, f).

Head (Fig. 1a) slightly wider than long, widest in eye region; frons tumid but weakly depressed at apex; occiput strongly and widely depressed; transverse and median sutures visible but not conspicuous; posterior margin strongly emarginated in middle. Eyes prominent, distinctly longer than the post-ocular length. Antennae (Fig. 1a, d) 17 segments or more (in holotype 15 left segments and 17 right segments remain), $1^{\text {st }}$ expanded apically, slightly shorter than the combined length of $2^{\text {nd }}$ to $4^{\text {th}}$; $2^{\text {nd }}$ minute, shorter than width; $3^{\text {rd }}$ long and slender; $4^{\text {th }}$ slightly shorter than $3^{\text {rd }} ; 5^{\text {th }}$ onwards segments gradually increasing in length and thinning up to $13^{\text {th }}$ and $14^{\text {th }}$. Pronotum (Fig. 1b) longer than broad, narrowed posteriorly, anteriorly convex, sides almost straight, hind margin subrotundate, median sulcus distinct, prozona tumid and well differentiated from flat metazona. Tegmina (Fig. 1b) well developed, humeral angles weak, costal margin straight, posterior margin obliquely convex, axillary angles weak, showing a broad triangular scutellum. Wings (Fig. 1b) well developed.

Prosternum (Fig. 1c) elongate, with a constriction at the point of attachment of forelegs. Mesosternum (Fig. 1c) broader than prosternum, more or less rounded, deeply constricted at the point of attachment of the midlegs, truncated posteriorly. Metasternum (Fig. 1c) hexagonal, constricted at point of attachment of hindlegs, emarginate posteriorly.

Abdomen (Fig. 1a) long, cylindrical, greatly enlarging from $7^{\text {th }}$ tergite onwards. Penultimate sternite (Figs 1f, 2a), relatively long, posterior margin weakly emarginated at middle. Ultimate tergite (Fig. 1a) transverse with two small, bifid, undulate depressions. Forceps (Fig. 1a, f) about as long as the ultimate tergite, trigonal with ridge only present in basal two-thirds, branches tapering apically with pointed tip and without curving.

Parameres (= external parameres; Figs 1g, 2b) with an internal tooth at apical onequarter and a small, deep concavity distal to it. Penis lobes (Figs 1g, 2c) slightly shorter than the parameres, each with a denticulated sclerite (= outer denticulated sclerite; ods), two differently shaped, serrated sclerites (mid serrated sclerite [mss] and inner serrated sclerite [iss]), a disc-shaped sclerite (ds), and a bifurcated virga. Virga (Figs 1g, 2c) with very short, unpaired part, and long paired part. Each branch of paired part convoluted, slender, but with well-developed flange, and tips widened with a whip-like distal process (wdp). 


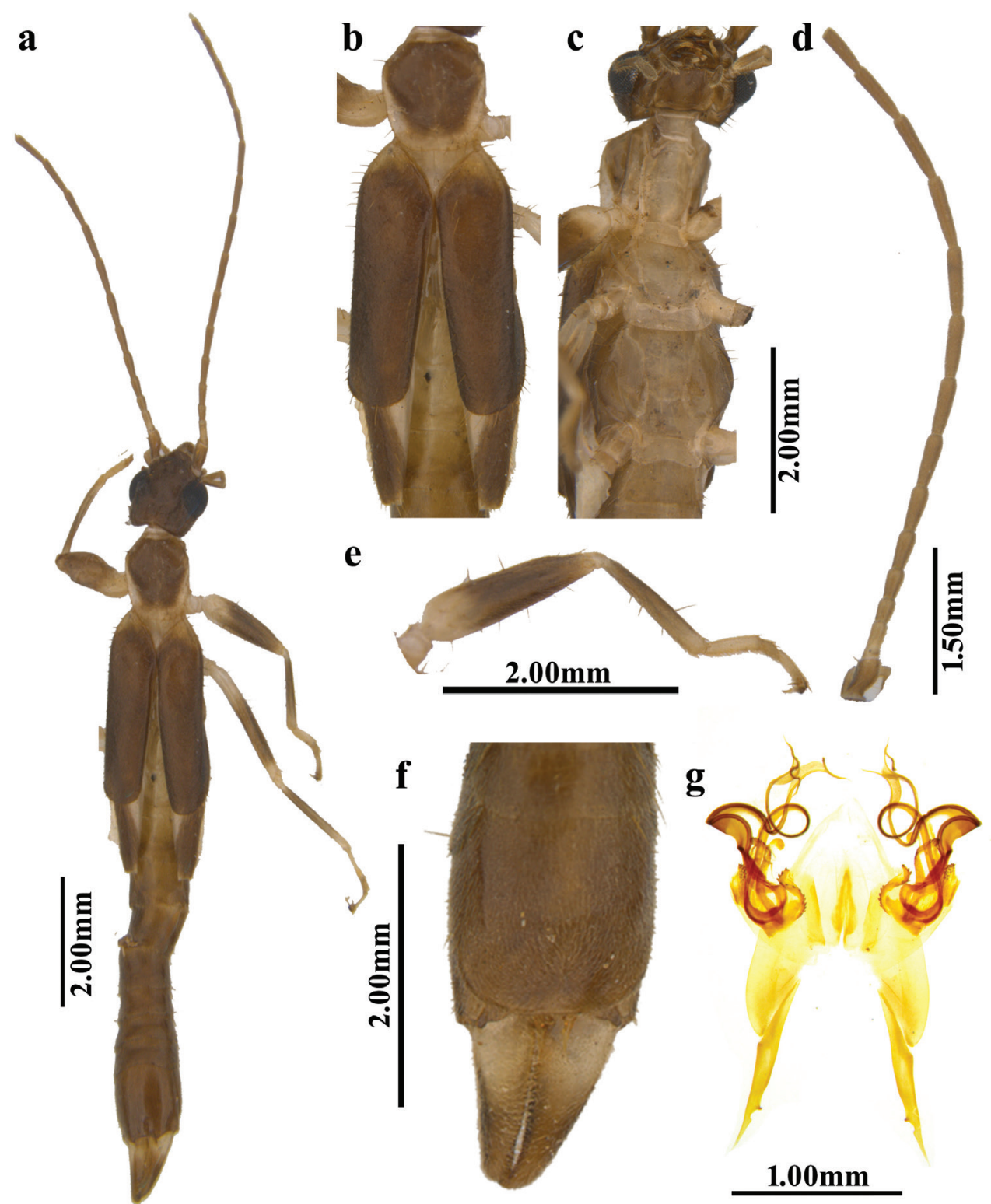

Figure I. Diplatys sahyadriensis sp. nov. (male holotype) a habitus b pronotum, tegmina and wings $\mathbf{c}$ thoracic sterna $\mathbf{d}$ left antenna $\mathbf{e}$ right foreleg $\mathbf{f}$ penultimate sternite and forceps $\mathbf{g}$ genitalia.

Female. Unknown.

Etymology. The specific epithet sahyadriensis refers to the type locality: the specimen was collected from the Sahyadri Ranges, which is a gateway to the Western Ghats of Karnataka.

Distribution. Only known from Shivamogga, Karnataka, India. 
Bioecology. The male specimen (holotype) was collected from whorls of sugarcane Saccharum officinarum L. (Angiospermae, Gramineae). The collection site is in a mixed area of sugarcane and paddy fields. Faecal pellets were seen on the leaves of sugarcane, suggesting that specimen had been in that place for some time, possibly taking advantage of this shaded spot.
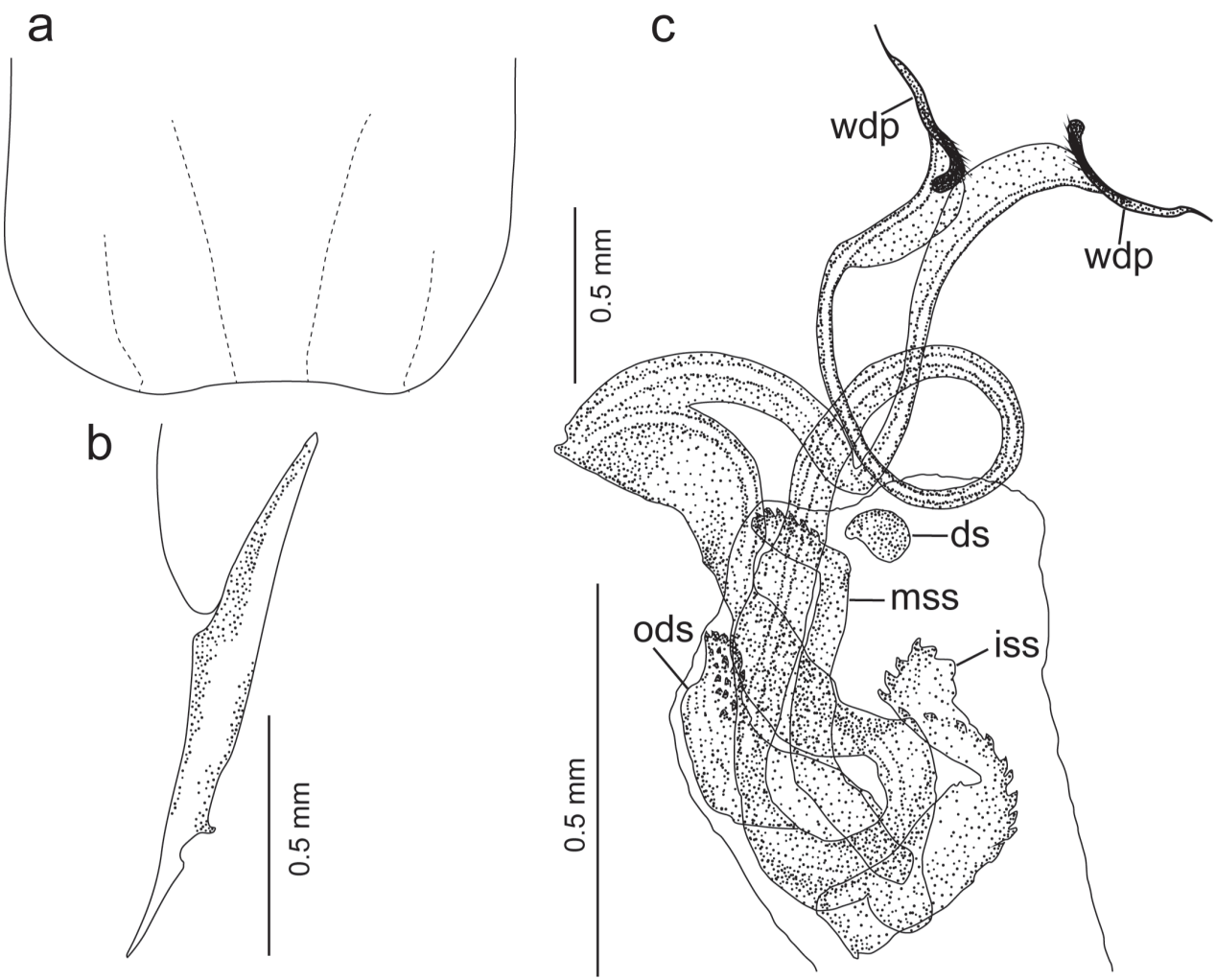

Figure 2. Diplatys sahyadriensis sp. nov. (male holotype) a posterior half of penultimate sternite $\mathbf{b}$ left paramere $\mathbf{c}$ left penis (in repose), virga with whip-like distal processes (wdp), and associated sclerites (ds, disc-shaped sclerite; iss, inner serrated sclerite; mss, mid serrated sclerite; ods, outer denticulated sclerite).

Table 2. Measurements ( $\mathrm{mm}$ ) of the male holotype of Diplatys sahyadriensis sp. nov.

\begin{tabular}{lcc}
\hline & Length & Measurement $(\mathbf{m m})$ \\
\hline Body without forceps & 11.12 \\
Head & 1.55 \\
Pronotum & 1.22 \\
Tegmen & & 3.00 \\
Forceps & Width & 1.30 \\
\hline & & \\
\hline Head & 1.57 \\
Pronotum & 1.22 \\
Tegmen & 1.00 \\
Ultimate tergite & 1.25 \\
\hline
\end{tabular}


Key to Diplatys species known from India and Sri Lanka (males only)

(Adopted from Srivastava 1988; ${ }^{*}=$ species known only from Sri Lanka)

$1 \quad$ Virga much reduced, represented by dots; instead, a long chitinous rod projects from penis lobe (According to Srivastava 1989)

Diplatys chowdhuryi Srivastava, 1989

Bifurcated virga present

2 Virga paired throughout its entire length

Diplatys confusus Hincks, 1955; Diplatys coelebs Hincks, 1955; Diplatys jawalagiriensis Kapoor, Bharadwaj \& Banerjee, 1971; Diplatys nathani Hincks, 1960; Diplatys dolens Hincks, 1957; Diplatys tikaderi Srivastava, 1988; Diplatys lefroyi Burr, 1910; or Diplatys menoni Kapoor \& Bharadwaj, 1968; see couplets 12-25 in the key by Srivastava (1988)

- Virga unpaired at base, sometimes forming a rounded vesicle or small protuberance; its length variable in relation to paired portion 3 Unpaired portion of virga about as long as or longer than the paired portion Diplatys propinquus Hincks, 1955*; Diplatys ernesti Burr, 1910*; Diplatys adjacens Hincks, 1955; Diplatys sinuatus Hincks, 1955; Diplatys santoshi Srivastava, 1975*; Diplatys nilgiriensis Hincks, 1955; or Diplatys carinatus Srivastava, 1988; see couplets $37-48$ in the key by Srivastava (1988) - $\quad$ Unpaired basal portion of virga very short to one-third of the paired portion Parameres internally with a sharp tooth at about the middle, apical half narrow and points externally. Unpaired part of virga short but dilated, forming an oval vesicle ..................................... Diplatys brindlei Steinmann, 1974

- $\quad$ Outer margin of parameres almost straight, apical half not obliquely pointing outward. Unpaired part of virga not forming a conspicuous oval-shaped vesicle Posterior margin of penultimate sternite with a pair of conspicuous projections and emarginate between these projections

Diplatys popovi Bey-Bienko, 1959

Posterior margin of penultimate sternite almost truncate, emarginate, or sinuate, but without conspicuous projections

. .6 Posterior margin of penultimate sternite almost truncate, or only feebly undulate

Posterior margin of penultimate sternite emarginate at middle or bisinuate..... 
8 Posterior margin of penultimate sternite emarginate at middle or bisinuate. Virga very long, extending beyond base of genitalia ....................................9

- $\quad$ Penultimate sternite posteriorly emarginate at middle. Virga short or long, but not extending beyond base of genitalia ................................................10

9 Penultimate sternite posteriorly bisinuate. Virga very long, extending beyond base of genitalia, paired part not flanged ... Diplatys chopardi Hincks, 1955

- $\quad$ Penultimate sternite weakly emerged at middle posteriorly. Paired part of virga convoluted and laterally provided with flange, each apex with a whiplike process.

Diplatys sahyadriensis Karthik, Kamimura \& Kalleshwaraswamy, sp. nov. 10 Virga apparently longer than penis lobe..... Diplatys excidens Hincks, 1954 - Virga shorter than or almost as long as penis lobe 11

11 Virga much shorter than $1 / 2$ of penis lobe; paired part stout and swollen..... Diplatys carli Srivastava, 1988

- $\quad$ Virga longer than $1 / 2$ of penis lobe; paired part slender ............................12 12 Inner pre-apical tooth of parameres strongly hooked.

Diplatys anamaliensis Srivastava, 1970

- $\quad$ Inner pre-apical tooth of parameres normal, not strongly hooked

..Diplatys greeni Burr, 1904

\section{Discussion}

In the present study, we follow Srivastava's $(1988,2013)$ classification of Diplatyinae, except for the treatment of Haplodiplatys Hincks, 1955, which is considered the sole genus of the family Haplodiplatyidae (Engel et al. 2017). Based mainly on the parameric characters, Steinmann (1974, 1986b) proposed to classify Diplatys sensu Hincks (1955) into four genera (Diplatys, Schizodiplatys Steinmann, 1974, Lobodiplatys Steinmann, 1974, and Circodiplatys Steinmann, 1986). Although Steinmann (1974) placed Diplatys conradti Burr, 1904 in Lobodiplatys, Zacher (1910) erected subgenus Paradiplatys Zacher, 1910, treating this species as its type. According to the Principle of Priority, Sakai (1982) resurrected the subgenus Paradiplatys as a full genus and synonymised Lobodiplatys with it. Engel and Haas (2007), who omitted to cite Sakai (1982), made the same proposal. This view was followed by Srivastava $(1988,2013)$ in classifying the Indian species of Diplatyinae into three genera: Diplatys, Paradiplatys, and Nannopygia Dohrn, 1863; Srivastava (1993b) considered Nannopygia a senior synonym of Schizodiplatys. Males of Diplatys possess a pair of elongate parameres with unarmed external margins (vs armed with a single movable epimerite in Paradiplatys), but with internal margins armed with one or two teeth, which are sometimes separated by a concavity. Occasionally, a concavity preceding or succeeding the pre-apical tooth is also present but parameres are not divided into two lobes with a cleft (vs cleft in Nannopygia). The elongate parameres of the new species, each with an internal tooth but without deep clefts or articulated structures, clearly indicate that the species is a member of Diplatys. 
Steinmann (1986b) proposed a subgeneric classification system for Diplatys (Table 1), mainly based on the relative lengths of virgal regions (paired and unpaird parts), especially those included in the penis lobe. However, some apparently closely related species can be classified into different subgenera according to this system (Gorokhov and Anisyutkin 1994). Therefore, we do not assign D. sahyadriensis sp. nov. to any subgenus, as done for some other Diplatys species described since Steinmann (1986b) (Table 1).

The male genitalia of $D$. sahyadriensis sp. nov. are unique in the genus in having several elaborations: a well-developed flange on the paired part of virgae, three differently shaped sclerites with serration (or denticulation) on the penis lobe, and a filament-like appendage at each virgal tip. Diplatys jawalagiriensis, which has been recorded from Karnataka and Tamil Nadu, also possesses flanged virgae (Kapoor et al. 1971; Srivastava 1988), which indicates a possible relationship with D. sahyadriensis sp. nov. According to the descriptions by Kapoor et al. (1971) and Srivastava (1988), however, no conspicuous associated sclerite is present in the penis lobe of this species.

Diplatys propinquus is a Sri Lankan Diplatys species possibly close to the new species. According to the descriptions and illustrations by Hincks (1955) and Srivastava (1988), each penis lobe includes three different, serrated or denticulated sclerites, which are very similar to those of $D$. sahyadriensis sp. nov. Little is known of the functions of sclerites observed on the penis lobe of earwigs. However, males of the ovoviviparous spongiphorid Marava arachidis (Yersin, 1860) possess a pair of triangular sclerites (genital hooks) on the penis lobe (Kamimura et al. 2016), and during copulation, the sclerites are firmly pressed against the opening region of the spermatheca, frequently resulting in wounds (Kamimura et al. 2016). At the same time, another spatulashaped sclerite is shallowly inserted into the spermatheca (female sperm storage organ), supporting the insertion of the narrow $(<10 \mu \mathrm{m}$ in diameter) but highly elongate (ca $20 \mathrm{~mm}$ ) virga (Kamimura et al. 2016). A similar division of roles among differently shaped accessory sclerites has been reported for another spongiphorid, Paralabellula dorsalis (Burmeister, 1838) (Briceño 1997; Kamimura and Ferreira 2017). Different types of denticulated or serrated accessory sclerites have also been reported for several other diplatyids (Hincks 1955; Sakai 1985; Steinmann 1986a; Srivastava 1988). Males of Diplatys flavicollis Shiraki, 1907 possess three different types of denticulated sclerites (saber-shaped, rod-shaped, and U-shaped) on each penis lobe (Kamimura 2004). During genital coupling, two lateral pockets in the female genital chamber receive the U- and rod-shaped sclerites, while the saber-shaped sclerite contacts the female subgenital plate (Kamimura 2004). The accessory sclerites of $D$. sahyadriensis sp. nov. may have similar functions in securely holding a female during copulation.

The filament with long spines at each virgal tip represents another characteristic structure of D. sahyadriensis sp. nov. In Diplatys, the Cameroonian D. longipennis Brindle, 1969 also possesses many spines, like barbs, but directly on each tip of the thin, highly elongate paired part of the virgae (Brindle 1969). These barb-like structures may be for the removal of rival sperm from female sperm storage organ(s), as known in several 
insect groups (Waage 1979). Males of the anisolabidid, Euborellia plebeja (Dohrn, 1863) also use their highly elongate virga, which is usually longer than the entire body, for removing rival sperm from the tubular spermatheca of mates (Kamimura 2000). However, in this species, a recurved flange at the virgal tip is considered responsible for sperm removal (Kamimura 2000). Although males of most earwig species directly insert a virga into the female spermatheca for transferring sperm during copulation (Kamimura 2014; Kamimura et al. 2019), D. flavicollis is an exception: the virgal tips are much wider than the spermathecal openings and ducts, indicating that physical removal of stored sperm by a virga is not feasible (Kamimura 2004). However, as in males, female genitalia are quite variable among diplatyid species (Popham 1965; Klass 2003). Future studies on the female genital structures and reproductive biology are warranted for $D$. sahyadriensis sp. nov. and other, related species.

Based on temperature and precipitation, India is divided into six regions: highland, humid subtropical, tropical wet and dry, arid, semiarid, and tropical wet zones (Senapati et al. 2013). Diplatys is most species rich in the tropical wet and dry zone (Table 1), which occupies a large part of the southern Indian peninsula. The tropical, rainy climate is responsible for the persistent warm or hot temperature, which normally does not fall below $18^{\circ} \mathrm{C}$. India hosts two climatic subtypes, the tropical monsoon climate and the tropical wet and dry climate. The most humid is the tropical monsoon climate, also known as tropical wet climate, which extends over a strip of south-western lowlands abutting the Malabar Coast, the Western Ghats, and southern Assam. These regions are characterised by moderate to high year-round temperatures, even in the foothills, and rainfall which is seasonal but heavy and typically more than 2,000 mm per year (Senapati et al. 2013). Most rainfall occurs between May and November, and this moisture is enough to sustain lush forests and other vegetation for rest of the year. The heavy monsoon rains are responsible for the exceptionally higher biodiversity of earwigs.

The new species of earwig, D. sahyadriensis sp. nov. described from sugarcane ecosystem in Western Ghats gives insight into the possible substantial diversity of this genera in India. There is a need to study its distribution, status, and role in agricultural and horticultural ecosystems.

\section{Acknowledgements}

CMK and CMK thank the Director of Research, Keladi Shivappa Nayaka University of Agricultural and Horticultural Sciences, Shivamogga, for providing the necessary facilities for the research. We thank Ranjith, Kavya yadav, Sandeep, Santrupti, and Loka Mounika for helping in the field. We are also grateful to two anonymous reviewers for their constructive comments, which greatly improved the manuscript. This research was partly supported by the Japan Society for the Promotion of Science via Grants-inAid for Scientific Research (Kakenhi) \#19K06746 to YK. 


\section{References}

Briceño RD (1997) Genitalic structure and copulation in Paralabella dorsalis (Dermaptera: Labbidae). Revista de Biología Tropical 45: 1107-1116.

Brindle A (1969) Récoltes de Ph. Bruneau de Miré au Cameroun (Dermaptera). Bulletin de l'Institut Français d'Afrique Noire 31: 58-71.

Deepak CK, Ghosh D (2018) Insecta: Dermaptera. In: Zoological Survey of India (Ed.) Faunal Diversity of Indian Himalaya. Zoological Survey of India, Kolkata, 265-272.

Engel MS, Haas F (2007) Family-group namesfor earwigs (Dermaptera). American Museum Novitates 3567(1): 1-20. https://doi.org/10.1206/0003-0082(2007)539[1:FNFED]2.0.CO;2

Engel MS, Huang D, Thomas JC, Cai C (2017) A new genus and species of pygidicranid earwigs from the Upper Cretaceous of southern Asia (Dermaptera: Pygidicranidae). Cretaceous Research 69: 178-183. https://doi.org/10.1016/j.cretres.2016.09.009

Gorokhov AV, Anisyutkin LN (1994) To the knowledge of Vietnam earwigs from the family Diplatyidae (Dermaptera). Trudy Zoologicheskogo instituta (Akademiia Nauk SSSR) 257: 59-71.

Hincks WD (1955) A systematic monograph of the Dermaptera of the world. Part I. Pygidicranidae: Diplatyinae. British Museum (Natural History), London, 132 pp.

Hopkins H, Maehr MD, Haas F, Deem LS (2018) Dermaptera Species File. Version 5.0/5.0. http://dermaptera.speciesfile.org [Accessed on 2022-2-21]

Kamimura Y (2000) Possible removal of rival sperm by the elongated genitalia of the earwig, Euborellia plebeja. Zoological Science 17(5): 667-672. https://doi.org/10.2108/zsj.17.667

Kamimura Y (2004) Mating behaviour and insemination in Diplatys flavicollis, an earwig with double-barreled penises and a variable number of female sperm-storage organs. Journal of Zoology 262(1): 37-46. https://doi.org/10.1017/S0952836903004370

Kamimura Y (2014) Pre- and postcopulatory sexual selection and the evolution of sexually dimorphic traits in earwigs (Dermaptera). Entomological Science 17(2): 139-166. https://doi.org/10.1111/ens.12058

Kamimura Y, Ferreira RL (2017) Earwigs from Brazilian caves, with notes on the taxonomic and nomenclatural problems of the Dermaptera (Insecta). ZooKeys 713: 25-52. https://doi.org/10.3897/zookeys.713.15118

Kamimura Y, Tee HS, Lee C-Y (2016) Ovoviviparity and genital evolution: A lesson from an earwig species with coercive traumatic mating and accidental breakage of elongated intromittent organs. Biological Journal of the Linnean Society. Linnean Society of London 118(3): 443-456. https://doi.org/10.1111/bij.12755

Kamimura Y, Yang CCS, Lee C-Y (2019) Fitness advantages of the biased use of paired laterally symmetrical penises in an insect. Journal of Evolutionary Biology 32(8): 844-855. https://doi.org/10.1111/jeb.13486

Kapoor VC, Bharadwaj RK, Banerjee SK (1971) Some new species of Dermaptera. Bulletin of Entomology 12: 28-40.

Klass KD (2003) The female genitalic region in basal earwigs (Insecta: Dermaptera: Pygidicranidae s.1.). Entomologische Abhandlungen 61: 173-225. 
Popham EJ (1965) The functional morphology of the reproductive organs of the Common earwig (Forficula auricularia) and other Dermaptera with reference to the natural classification of the order. Journal of Zoology 146: 1-43. https://doi.org/10.1111/j.1469-7998.1965. tb05198.x

Sakai S (1982) A new proposed classification of the Dermaptera with special reference to the check-list of the Dermaptera of the world. Bulletin of Daito Bunka University 20: 1-108.

Sakai S (1985) Dermapterorum Catalogus XVI-XVIII: Iconographia I-III. Pygidicranidae and Diplatyidae. Daito Bunka University, Tokyo, 1080 pp.

Senapati MR, Behera B, Mishra SR (2013) Impact of climate change on Indian agriculture \& its mitigating priorities. American Journal of Environmental Protection 1(4): 109-111. https://doi.org/10.12691/env-1-4-6

Srivastava GK (1988) Fauna of India and the Adjacent Countries, Dermaptera Part I: Pygidicranoidea. Zoological Survey of India, Kolkata, 268 pp.

Srivastava GK (1989) Zoological Survey of India. State Fauna Series 1: Fauna of Orissa (Part 2): $147-170$.

Srivastava GK (1993a) Zoological Survey of India. State Fauna Series 3: Fauna of West Bengal (Part 4): 369-459.

Srivastava GK (1993b) Taxonomic status of certain genera of Pygidicranidae (Demiaptera). Records of the Zoological Survey of India 92: 41-51.

Srivastava GK (2013) Fauna of India and the Adjacent Countries, Dermaptera Part III: Apachyoidea and Forficuloidea. Zoological Survey of India, Kolkata, 268 pp.

Steinmann H (1974) A new generic classification of the species group of Diplatys Serville (Dermaptera, Pygidicranidae). Acta Zoologica Hungarica 20: 187-205.

Steinmann H (1986a) Dermaptera. Catadermaptera I. Das Tierreich 102: 1-343.

Steinmann H (1986b) A new generic classification for the Diplatys species-groups (Dermaptera: Pygidicranidae). Acta Zoologica Hungarica 32: 169-179.

Waage JK (1979) Dual function of the damselfly penis: Sperm removal and transfer. Science 203(4383): 916-918. https://doi.org/10.1126/science.203.4383.916

Zacher F (1910) Beitrag zur Kenntnis der Pygidicraniden und Diplatyiden (Dermatera). Entomologische Rundschau 27: e105. 